\title{
Survival of Preterm Singleton Deliveries: A Population-Based Retrospective Study
}

\author{
Boubakari Ibrahimou, ${ }^{1}$ Sireesha Kodali, ${ }^{2}$ and Hamisu Salihu ${ }^{3}$ \\ ${ }^{1}$ Department of Biostatistics, Robert Stempel College of Public Health \& Social Work, Florida International University, \\ 11200 SW 8th Street, AHC5 465, Miami, FL 33199, USA \\ ${ }^{2}$ School of Dentistry, University of Louisville, 501 S. Preston Street, Louisville, KY 40202, USA \\ ${ }^{3}$ Department of Family and Community Medicine, Baylor College of Medicine, 3701 Kirby Drive, Suite 600, Houston, TX 77098, USA
}

Correspondence should be addressed to Boubakari Ibrahimou; bibrahim@fiu.edu

Received 15 May 2015; Revised 8 August 2015; Accepted 8 September 2015

Academic Editor: Peter N. Lee

Copyright ( $) 2015$ Boubakari Ibrahimou et al. This is an open access article distributed under the Creative Commons Attribution License, which permits unrestricted use, distribution, and reproduction in any medium, provided the original work is properly cited.

\begin{abstract}
Aim. To identify sociodemographic and medical characteristics associated with preterm birth survival. Methods. A retrospective study of singleton births was performed using Missouri linked data for the years 1978 to 2005. We computed hazard ratios (HR) and $95 \%$ confidence intervals (CI) using Cox proportional hazards model. Results. High rates of infant, neonatal, and postneonatal mortality were observed among preterm as compared to term births. White are at low risk for postneonatal (HR $=0.77$, CI: 0.65 , $0.90)$ and infant mortality ( $\mathrm{HR}=0.90, \mathrm{CI}: 0.81,0.99)$ compared to blacks. We observed increased risks of all mortality types for preterm deliveries by caesarean section (neonatal $\mathrm{HR}=1.53$, CI: 1.40, 1.68; postneonatal HR = 1.39, CI: 1.22, 1.58; infant HR = 1.37, CI: 1.27, 1.48). As compared to nonsmokers, preterm singletons born to smoking mothers are $69 \%$ more likely to experience postneonatal mortality and have a $17 \%$ increased risk for infant death. Conclusions. Caesarean section is associated with increased risk of all types of mortality. Racial disparity is still a concern. Further research is required to identify the detailed differences in structure and procedures that result in the disadvantage associated with preterm birth especially with respect to caesarean section and race.
\end{abstract}

\section{Introduction}

Preterm birth, defined as birth at less than 37 completed weeks or 259 days of gestation, is the second leading cause of infant deaths (17\%) in the United States [1]. The leading causes of infant mortality in the United States are preterm birth, low birth weight, and birth defects, preterm birth and low birth weight being major contributors to infant mortality [2-4]. As per the CDC report in 2004, 1 in 8 US infants were born preterm compared to 1 in 16 in France and Sweden [5]. More than $50 \%$ of perinatal and long-term morbidity and $75 \%$ of all perinatal mortality are associated with preterm births $[6,7]$. Worldwide an estimated $11.1 \%$ of all live births in 2010 were born preterm and preterm birth is a risk factor in over $50 \%$ of all neonatal deaths $[8,9]$. Preterm birth is also the dominant risk factor for neonatal mortality, reporting about one million deaths annually due to infections [10]. According to the CIA fact book 2012, United States ranks 50 in infant mortality with six deaths reported for every 1,000 live births; of which two-thirds are likely to occur among the preterm infants [1].

Infants born preterm are more likely than infants born full term to die during the neonatal period (first 28 days) and infancy (first year), and mortality rates increase proportionally with decreasing gestational age or birth weight $[3,11-$ 13]. Gestational period and low birth weight are the major determinants of survival of a preterm baby. Early preterm and low birth weight infants $(<2500 \mathrm{~g})$ have a very poor prognosis of survival compared to those of late preterm infants with more birth weight ( $2500 \mathrm{~g}$ or more) and the survival rate increases proportionately with the length of gestation. Infant mortality rate for very low birth weight infants $(<1,500 \mathrm{~g})$ was 244.95 infant deaths per 1,000 live births, which was more than 100 times the rate of 2.30 deaths per 1000 live births for infants weighing 2,500 grams or more [14]. About $86.0 \%$ of infants with birth weights of less than 500 grams died within 
the first year of life, although reporting of deaths among these very small infants may be incomplete [14].

Survival of preterm babies can be affected by maternal obstetric and gynecological factors and biological and socioeconomic factors that extend from prenatal through postnatal periods and can be categorized into three groups. Group I or pregnancy related factors are medical risk factors such as hypertension, uterine malformations, vaginal bleeding during pregnancy, premature rupture of placental membranes (PPROM), placenta previa, polyhydramnios or oligohydramnios, short cervix, mental disturbances (anxiety, depression), and adverse habits such as smoking, alcohol consumption, and drug intake. Group II are factors related to maternal demographics such as pregnancy age $(<17$ and $>35 \mathrm{yrs})$, educational level, marital status, socioeconomic status, short interpregnancy interval, and other social factors (poor access to care, physical abuse). Group III are factors associated with infections such as bacterial vaginosis, trichomoniasis, chlamydial infection, gonorrhea, syphilis, urinary tract infection, viral infections, intrauterine infections, short cervical length between 14 and 28 weeks, positive interferon (IFN) between 22 and 34 weeks, and uterine contractions [6].

Dramatic decline in infant and neonatal mortality and gestational-age specific mortality over the last several decades has been attributed to improvements in obstetric and neonatal intensive care, especially for infants born preterm and small for gestational age $[12,15]$. However, the United States most recently had an increase in infant mortality from 6.8 in 2001 to 7.0 per 1,000 live births in 2002 [16] and an increase in the preterm birth rate to 12.3 percent in 2003 from 2002 [3]. In spite of the increasing rate of infant mortality, related research and attempts to reduce the rates are not increased. So far research has been conducted for determining the effect of mode of delivery on the survival rate, the results of which are unclear regarding the benefits of $\mathrm{C}$-sections in increasing the survival rate for early and very low birth weight preterm births [6]. Positive results were drawn for low gestational period and low birth weight causing increased neonatal mortality of preterm births. Research has been conducted towards the intervention procedures such as administration of antenatal corticosteroids to pregnant women at high risk of preterm birth as an attempt to reduce neonatal mortality.

Researchers have been focused more on trends involving the occurrence of and consequent deaths of preterm births over a period of time to a certain degree than on the rates and factors affecting the survival of preterm babies. The direct evidence supporting increased tendency of deaths from preterm births and the outcome of maternal risk factors on the associated mortality rates is yet to be explored. The main purpose of this paper is to establish the survival rates of preterm births by estimating the risk for infant, neonatal, and postneonatal mortality in the midst of preterm singletons using Missouri maternally linked data files from 1978 to 2005.

\section{Methods}

We obtained a maternally linked dataset from the Missouri Department of Health for the period of 1978 through 2005. The dataset provides a wide range of maternal and fetal information, starting from the pregnancy care until one year after delivery. Variables included in our study are maternal sociodemographic characteristics, maternal adverse life style choices such as smoking and drinking, pregnancy risk factors and labor complications, gestational age, type (caesarean section or vaginal delivery) and date of delivery, birth weight, infant sex, and date of death. Our primary outcome of interest was survival rates of preterm singletons.

Survival rates were determined by examining infant mortality associated with all the study variables. Further, infant mortality was stratified into neonatal mortality (death within 28 days of birth), postneonatal mortality (death between 28 and 364 days), and infant mortality (death within 365 days). Using gestational age we classified singletons births into two categories (preterm and term deliveries). For survival rates, we restricted the analysis to preterm babies. Maternal age was categorized as less than 18 years and 18-35 years and greater than 35 years; maternal race includes whites, blacks, and others (other Asian or Pacific Islander). We subdivided maternal and paternal educational levels into two groups: $<12$ years and $\geq 12$ years of education.

Chi-square tests were performed to assess the proportional differences between preterm and term births in relation to sociodemographic and infant mortality indices. Pregnancy rates, labor complications, infant mortality, neonatal mortality, and postneonatal mortality rates were calculated by dividing the total number of cases by the total number of singleton live births and multiplying the outcome by 1,000 . We performed survival analysis using " $R$ " statistical software, version 3.0.2. The Cox proportional hazard model was employed to perform the survival analysis. We used the Cox proportional hazards regression model to derive adjusted hazard ratios after testing for nonviolation of the proportionality assumption in each case. We confirmed this by plotting the log-negative-log of the Kaplan-Meier estimates of the survival function versus the log of time. The resulting curves were parallel [17]. Adjusted hazard ratios were derived by loading all the variables that were considered to be potential confounders into the model. The computed hazard was determined by

$$
h(t)=h_{0}(t) x \exp \left\{b_{1} x_{1}+b_{2} x_{2}+\cdots+b_{p} x_{p}\right\},
$$

where the hazard function is represented by $h(t)$ and is determined by a group of covariates $\left(x_{1}, x_{2}, \ldots, x_{p}\right)$ whose effect is measured by the size of the individual coefficients $\left(b_{1}, b_{2}, \ldots, b_{p}\right)$ and $t$ is the survival time of infancy. All hypothesis tests were carried out with type 1 error rate set at $5 \%$.

\section{Results}

Of the total of 632,258 singletons births considered in our study, 572,694 (90.58\%) were term births, while 59,564 (9.42\%) were preterm births. Comparing mothers by birth type (preterm versus term), we identified significant differences in age, race, marital status, and prenatal smoking status, Table 1. We observed preterm births to be higher among unmarried women, black and other non-white races, women 
TABLE 1: Sociodemographic characteristics of the study population.

\begin{tabular}{|c|c|c|c|}
\hline Predictors & $\begin{array}{c}\text { Preterm birth }^{+} \\
N(\%)\end{array}$ & $\begin{array}{c}\text { Term birth } \\
N(\%)\end{array}$ & $P$ value $^{+}$ \\
\hline Maternal age & & & $<0.001$ \\
\hline$<18$ years & $2,013(3.38)$ & $12,577(2.20)$ & \\
\hline $18-35$ years & $52,756(88.57)$ & $519,382(90.69)$ & \\
\hline$>35$ years & $4,795(8.05)$ & $40,735(7.11)$ & \\
\hline Maternal race & & & $<0.001$ \\
\hline White & $50,817(85.32)$ & $524,326(91.56)$ & \\
\hline Black & $7,536(12.65)$ & $38,788(6.77)$ & \\
\hline Other & $1,211(2.03)$ & $9,580(1.67)$ & \\
\hline Infant sex & & & $<0.001$ \\
\hline Male & $32,366(54.34)$ & $291,659(50.93)$ & \\
\hline Female & $27,198(45.66)$ & $281,035(49.07)$ & \\
\hline Maternal educational level & & & $<0.001$ \\
\hline$<12$ years & $10,943(18.37)$ & $79,206(13.83)$ & \\
\hline$>12$ years & $48,621(81.63)$ & $493,488(86.17)$ & \\
\hline Paternal educational level & & & $<0.001$ \\
\hline$<12$ years & $9,910(16.64)$ & $74,940(13.09)$ & \\
\hline$>12$ years & $49,654(83.36)$ & $497,754(86.91)$ & \\
\hline Marital status & & & $<0.001$ \\
\hline Married & $47,562(79.85)$ & $491,172(85.77)$ & \\
\hline Not married & $12,002(20.15)$ & $81,522(14.23)$ & \\
\hline Maternal smoking & & & $<0.001$ \\
\hline Yes & $13,157(22.09)$ & $97,363(17.00)$ & \\
\hline No & $46,407(77.91)$ & $475,331(83.00)$ & \\
\hline Maternal drinking & & & 0.027 \\
\hline Yes & $822(1.38)$ & $7,283(1.27)$ & \\
\hline No & $58,742(98.62)$ & $565,411(98.73)$ & \\
\hline
\end{tabular}

${ }^{+} P$ values $<0.05$ were considered significant.

Other race = Indian, Chinese, Japanese, Hawaiian, Filipino, Asian Indian, Korean, Samoan, Vietnamese, Guamanian, and other Asian or Pacific Islander race.

less than 18 years old or greater than 35 years old, male infants, and infants with parents less than 12 years of education and smoking or drinking mothers. For both preterm and term births, over $85 \%$ of the mothers were whites and fell into the age group of 18 to 35 years. Compared to younger mothers of less than 18 years, older mothers of more than 35 years of age delivered more preterm babies (3.38\% versus $8.05 \%$ ).

Table 2 presents the crude frequencies for pregnancy and labor complications in the study population. Rates are observed to be significantly higher for preterm births compared to term births. In particular, there is a remarkable difference of caesarean section among preterm births $(202.72 / 1,000)$ as opposed to term births $(124.46 / 1,000)$.

Table 3 gives details on frequencies of infant mortality rates by birth type (preterm and term births). Compared to term births $(1.13 \%)$, neonatal death rates were 23.5 times higher among preterm births (26.48\%). Infant mortality rates were observed to be the highest among preterm births (33.01\%) as to compare to term births (2.92\%). Postneonatal mortality rates were 3.63 times more for preterm births (6.53\%) than for term births (1.79\%).

Adjusted HR for neonatal, postneonatal, and infant mortality among preterm births in relation to selected maternal risk factors are provided in Table 4 . Single mothers showed reduced risk for neonatal death $(\mathrm{HR}=0.88, \mathrm{CI}: 0.78-0.99)$ and high risk of postneonatal death $(\mathrm{HR}=1.27$, CI: $1.12-$ 1.45). There is no significant difference in preterm death with respect to maternal age for all three types of infant mortalities. For race, white mothers had a reduced risk of postneonatal death $(\mathrm{HR}=0.77, \mathrm{CI}: 0.65-0.90)$ and infant death $(\mathrm{HR}=0.90$, CI: 0.81-0.99) compared to blacks. Other non-whites have also a reduced risk of postneonatal mortality $(\mathrm{HR}=0.60, \mathrm{CI}$ : 0.37-0.97) compared to blacks. In all mortality types, females showed lower risk compared to males (neonatal mortality $(\mathrm{HR}=0.85, \mathrm{CI}: 0.78,0.93)$, postneonatal mortality $(\mathrm{HR}=$ $0.69, \mathrm{CI}: 0.62,0.77)$, and infant death rates $(\mathrm{HR}=0.79, \mathrm{CI}$ : $0.74,0.84))$.

Paternal education also plays an important role in reducing preterm mortality rates. For 12 or more years educated father, a low risk was observed for all infant mortality types (neonatal mortality ( $\mathrm{HR}=0.86, \mathrm{CI}: 0.76,0.97)$, postneonatal mortality $(\mathrm{HR}=0.69, \mathrm{CI}: 0.61,0.80)$, and infant death rates $(\mathrm{HR}=0.79$, CI: 0.72-0.86) $)$. Similarly mother's education is also important. Low risk was observed if the mother has 12 or more years of education for postneonatal $(\mathrm{HR}=0.79$, CI: 0.69-0.92) and infant death (HR $=0.86, \mathrm{CI}: 0.78-0.94)$. Maternal smoking increased the risk for postneonatal death by $69 \%(\mathrm{HR}=1.69, \mathrm{CI}: 1.50-1.91)$ and infant death by $17 \%$ $(\mathrm{HR}=1.17, \mathrm{CI}: 1.08-1.27)$. Premature babies born through caesarean section were at higher risk for neonatal $(\mathrm{HR}=1.53$, 
TABLE 2: Incidence of later complications (rates per 1000 live births) in preterm and term births.

\begin{tabular}{lccc}
\hline Labor complication & Preterm & Term & $P$ value \\
\hline Anemia & $1,047(17.58)$ & $6,280(10.97)$ & $<0.001$ \\
Eclampsia & $131(2.20)$ & $320(0.56)$ & $<0.001$ \\
Preeclampsia & $5,075(85.20)$ & $19,143(33.43)$ & $<0.001$ \\
Insulin-dependent diabetes & $692(11.62)$ & $2,799(4.89)$ & $<0.001$ \\
Other forms of diabetes mellitus & $1,545(25.94)$ & $11,550(20.17)$ & $<0.001$ \\
Chronic hypertension & $974(16.35)$ & $3,894(6.80)$ & $<0.001$ \\
Placental abruption & $2,183(36.65)$ & $2,423(4.23)$ & $<0.001$ \\
Placenta previa & $978(16.42)$ & $1,323(2.31)$ & $<0.001$ \\
Cesarean section & $12,075(202.72)$ & $71,276(124.46)$ & $<0.001$ \\
Renal disease & $264(4.43)$ & $1,099(1.92)$ & $<0.001$ \\
Rh sensitization & $362(6.08)$ & $2,943(5.14)$ & 0.003 \\
\hline
\end{tabular}

TABLE 3: Incidence per mortality type (rates per 1000 live births) in preterm and term births.

\begin{tabular}{lccr}
\hline Type of mortality & Preterm births & Term births & $P$ value \\
\hline Neonatal death $(<28$ days $)$ & $1577(26.48)$ & $648(1.13)$ & $<0.001$ \\
Postneonatal death $(28-364$ days $)$ & $389(6.53)$ & $1026(1.79)$ & $<0.001$ \\
Infant death $(1-364$ days) & $1966(33.01)$ & $1674(2.92)$ & $<0.001$ \\
\hline
\end{tabular}

TABLE 4: Adjusted hazards ratios (HR) for the association between pregnancy risk factors and early mortality among singletons, Missouri, 1978-2005.

\begin{tabular}{|c|c|c|c|}
\hline Predictor & $\begin{array}{c}\text { Neonatal death } \\
\text { HR }(\mathrm{CI})\end{array}$ & $\begin{array}{c}\text { Postneonatal death } \\
\text { HR (CI) }\end{array}$ & $\begin{array}{c}\text { Infant death } \\
\text { HR (CI) }\end{array}$ \\
\hline \multicolumn{4}{|l|}{ Marital status } \\
\hline Married & 1.00 & 1.00 & 1.00 \\
\hline Unmarried & $0.88(0.78-0.99)$ & $1.27(1.12-1.45)$ & $1.02(0.94-1.12)$ \\
\hline \multicolumn{4}{|l|}{ Maternal age } \\
\hline Less than 18 yrs & $1.13(0.89-1.43)$ & $0.95(0.72-1.25)$ & $1.02(0.85-1.22)$ \\
\hline $18-35$ years & 1.00 & 1.00 & 1.00 \\
\hline More than 35 years & $0.99(0.86-1.16)$ & $0.89(0.71-1.12)$ & $0.97(0.86-1.10)$ \\
\hline \multicolumn{4}{|l|}{ Maternal race } \\
\hline White & $0.97(0.86-1.10)$ & $0.77(0.65-0.90)$ & $0.90(0.81-0.99)$ \\
\hline Black & 1.00 & 1.00 & 1.00 \\
\hline Other & $1.02(0.73-1.43)$ & $0.60(0.37-0.97)$ & $0.83(0.63-1.09)$ \\
\hline \multicolumn{4}{|l|}{ Infant sex } \\
\hline Female & $0.85(0.78-0.93)$ & $0.69(0.62-0.77)$ & $0.79(0.74-0.84)$ \\
\hline Male & 1.00 & 1.00 & 1.00 \\
\hline \multicolumn{4}{|l|}{ Maternal educational } \\
\hline Less than 12 years & 1.00 & 1.00 & 1.00 \\
\hline 12 years or more & $0.91(0.80-1.04)$ & $0.79(0.69-0.92)$ & $0.86(0.78-0.94)$ \\
\hline \multicolumn{4}{|l|}{ Paternal educational } \\
\hline Less than 12 yrs & 1.00 & 1.00 & 1.00 \\
\hline 12 years or more & $0.86(0.76-0.97)$ & $0.69(0.61-0.80)$ & $0.79(0.72-0.86)$ \\
\hline \multicolumn{4}{|l|}{ Maternal smoking } \\
\hline Yes & $0.90(0.81-1.00)$ & $1.69(1.50-1.91)$ & $1.17(1.08-1.27)$ \\
\hline No & 1.00 & 1.00 & 1.00 \\
\hline \multicolumn{4}{|l|}{ Type of delivery } \\
\hline Caesarean section & $1.53(1.40,1.68)$ & $1.39(1.22,1.58)$ & $1.37(1.27,1.48)$ \\
\hline Vaginal birth & 1.00 & 1.00 & 1.00 \\
\hline Gestational age (week) & $0.87(0.86-0.89)$ & $1.07(1.04-1.10)$ & $0.91(0.90-0.93)$ \\
\hline Birth weight (gram) & $0.9992(0.9991-0.9993)$ & $0.9992(0.999-0.9993)$ & $0.9992(0.9992-0.9993)$ \\
\hline
\end{tabular}


CI: $1.40-1.68)$, postneonatal ( $\mathrm{HR}=1.39$, CI: $1.22-1.58)$, and infant deaths (HR $=1.37, \mathrm{CI}: 1.27-1.48)$. Increase in gestational age and birth weight are both associated with reduced risk for all mortality except an increased risk of postneonatal observed with increasing gestational age $(\mathrm{HR}=$ 1.07, CI: 1.04-1.10).

\section{Discussion}

This paper provides new evidence in determining the association between maternal sociodemographic characteristics and infant mortality among preterm deliveries. The study showed that preterm babies born to black women, least educated parents, smokers, teenagers, and unmarried mothers have increased risk of infant mortality. In addition, caesarean section delivery and reduced gestational period elevated the risk for infant death among preterm births. These findings were generally consistent across various study designs.

The study findings indicate that racial disparities influence the rate of infant death, as white mothers experienced lower risk of losing their babies than blacks even among preterm births. This confirm the results by Hogue and Hargraves [18], indicating that black babies in general were twice more at risk for death compared to white babies. This could be explained by the reduction of access to healthcare experienced by blacks. While dealing with the structural barriers to healthcare and personal insults against race, black women had to meet with excess release of stress hormones and pregnancy induced hypertension [18].

An interesting finding in our study is the high rate of caesarean sections among preterm births and the high rate of mortality associated to that subgroup. We observed that caesarean sections heightened the risk of all types of infant deaths. Unfortunately the dataset lacks information on whether these caesarean sections were elective or not.

Preterm babies born to single mothers have an increased risk for postneonatal and infant deaths which highlights the importance of having both parents during childhood. Though statistically not significant, teenage deliveries showed increased risk for neonatal and infant deaths, while older women ( $>35$ years) see an advantage by having lower risk compared to mothers between the age of 18 and 35 .

Another interesting finding was that females were at lower risk for all forms of infant death as compared to male singletons. The difference between male and female infant survival rates could be linked to the genetic factors. Presence of double lineage $\mathrm{X}$ chromosomes in females offers them better survival over the male counterparts, who have single $\mathrm{X}$ chromosome received from one cell line [19].

A finding in this study suggests that preterm babies born to least educated mothers were more at risk for infant death. Maternal educational level acts as an important indicator to estimate the socioeconomic status. In general, with increase in educational level, there would be a rise in socioeconomic status. In addition, higher socioeconomic status provides an opportunity for better awareness of health problems and access to prenatal care. In United States, babies born to least educated mothers were 2.3 times more at risk for infant death as compared to college graduates [18].
Our study highlights the effect of maternal smoking on infant survival rates. In general, prenatal smoking is considered a risk factor for pregnancy complications such as placental abruption, preeclampsia, stillbirth, and premature rupture of membranes. Women with these pregnancy disorders were more prone to deliver preterm babies, who were more at risk for infant deaths compared to term babies. In our assessment, smoking was observed to have a significant effect on survival rates of preterm births. Compared to nonsmokers, smoking mothers showed increased postneonatal and infant death rates of preterm babies. However, actual mechanism explaining the association between maternal smoking and infant survival is unknown.

Our results showed that black women had the greatest odds for postneonatal and infant mortality as compared to whites and others. The black-white disparity is a persistent finding in morbidity/mortality studies. A recent study found that exposure to air particulate pollutants widened the black-white disparity in feto-infant morbidity outcomes considerably [20]. These findings are of immense importance since attempts to narrow the black-white gap in feto-infant morbidity and mortality have, so far, not been successful, frustrating the attainment of the expired Healthy People 2010 objective. One of the factors for this lack of progress in reducing or eliminating black-white disparity is our poor understanding of modifiable risk factors.

Our study has some limitations. The group for other race is broad and included Indian, Chinese, Japanese, Hawaiian, Filipino, Asian Indian, Korean, Samoan, Vietnamese, Guamanian, and other Asian or Pacific Islander groups. Preterm babies born to mothers of other race were at high risk for neonatal death. However, we could not identify the significant maternal race to cause infant deaths from this other group. Additionally there was a high rate of caesarean deliveries among the preterm births and that caesarean section was associated with high risk of all types of mortality among preterm births. Unfortunately we were not able to determine if these caesarean sections were elective or due to emergency which could underline other pregnancy complications.

A key strength in our study is the sample size. We had huge population-based data. We extracted over 632,258 singleton births from a total of $1,035,547$ records. The large sample size confers the advantage of validity and reliability making it generalized to a large population. There were no issues of sample error; hence, parameters estimated are a reflection of true population value. Assessment of a population database makes our outcome less likely to be influenced by selection bias and provides valuable information for future research in singleton preterm births.

\section{Conflict of Interests}

The authors declare that there is no conflict of interests regarding the publication of this paper.

\section{References}

[1] W. M. Callaghan, M. F. MacDorman, S. A. Rasmussen, C. Qin, and E. M. Lackritz, "The contribution of preterm birth to infant 
mortality rates in the United States," Pediatrics, vol. 118, no. 4, pp. 1566-1573, 2006.

[2] G. R. Alexander, M. Kogan, D. Bader, W. Carlo, M. Allen, and J. Mor, "US birth weight/gestational age-specific neonatal mortality: 1995-1997 rates for whites, hispanics, and blacks," Pediatrics, vol. 111, no. 1, pp. e61-e66, 2003.

[3] J. A. Martin, B. E. Hamilton, P. D. Sutton, S. J. Ventura, F. Menacker, and M. L. Munson, "Births: final data for 2003," National Vital Statistics Reports, vol. 54, no. 2, pp. 1-116, 2005.

[4] J. Petrini, K. Damus, R. Russell, K. Poschman, M. J. Davidoff, and D. Mattison, "Contribution of birth defects to infant mortality in the United States," Teratology, vol. 66, no. 1, pp. S3S6, 2002.

[5] F. M. Macdorman and T. J. Mathews, "Behind international rankings of infant mortality: how the United States compares with Europe," NCHS Data Brief 23, National Center for Health Statistics, 2009.

[6] R. L. Goldenberg and E. M. McClure, "The epidemiology of preterm birth," in Preterm Birth: Prevention and Management, V. Berghella, Ed., chapter 4, Wiley-Blackwell, Oxford, UK, 2010.

[7] J. Lumley, "1 The epidemiology of preterm birth," Bailliere's Clinical Obstetrics and Gynaecology, vol. 7, no. 3, pp. 477-498, 1993.

[8] H. Blencowe, S. Cousens, D. Chou et al., "Born Too Soon: the global epidemiology of 15 million preterm births," Reproductive Health, vol. 10, supplement 1, article S2, 2013.

[9] E. Bibby and A. Stewart, "The epidemiology of preterm birth," Neuro Endocrinology Letters, vol. 25, supplement 1, pp. 43-47, 2004.

[10] J. E. Lawn, M. G. Gravett, T. M. Nunes, C. E. Rubens, and C. Stanton, "Global report on preterm birth and stillbirth (1 of 7): definitions, description of the burden and opportunities to improve data," BMC Pregnancy and Childbirth, vol. 10, supplement 1, article S1, 2010.

[11] G. R. Alexander, M. D. Kogan, and J. H. Himes, "1994-1996 U.S. Singleton birth weight percentiles for gestational age by race, hispanic origin, and gender," Maternal and Child Health Journal, vol. 3, no. 4, pp. 225-231, 1999.

[12] M. C. Allen, G. R. Alexander, M. E. Tompkins, and T. C. Hulsey, "Racial differences in temporal changes in newborn viability and survival by gestational age," Paediatric and Perinatal Epidemiology, vol. 14, no. 2, pp. 152-158, 2000.

[13] J. A. Lemons, C. R. Bauer, W. Oh et al., "Very low birth weight outcomes of the national institute of child health and human development neonatal research network, January 1995 through December 1996," Pediatrics, vol. 107, no. 1, p. E1, 2001.

[14] M. F. MacDorman and T. J. Mathews, "The challenge of infant mortality: have we reached a plateau?" Public Health Reports, vol. 124, no. 5, pp. 670-681, 2009.

[15] G. R. Alexander and M. Slay, "Prematurity at birth: trends, racial disparities, and epidemiology," Mental Retardation \& Developmental Disabilities Research Reviews, vol. 8, no. 4, pp. 215-220, 2002.

[16] M. F. MacDoman, J. Martin, T. J. Mathews et al., "Explaining the 2001-2002 infant mortality increase: data from the linked birthinfant death dataset," National Vital Statistics Reports, vol. 53, no. 12, pp. 1-24, 2005.

[17] D. R. Cox, "Regression models and life-tables," Journal of the Royal Statistical Society B, vol. 34, no. 2, pp. 187-220, 1972.

[18] C. J. R. Hogue and M. A. Hargraves, "Class, race, and infant mortality in the United States," American Journal of Public Health, vol. 83, no. 1, pp. 9-12, 1993.
[19] B. Ibrahimou, H. M. Salihu, G. English, C. Anozie, G. Lartey, and G. Dagne, "Twins born over weekends: are they at risk for elevated infant mortality?" Archives of Gynecology and Obstetrics, vol. 286, no. 6, pp. 1349-1355, 2012.

[20] H. M. Salihu, B. Ibrahimou, E. M. August, and G. Dagne, "Risk of infant mortality with weekend versus weekday births: a population-based studyjog," The Journal of Obstetrics and Gynaecology Research, vol. 38, no. 7, pp. 973-979, 2012. 


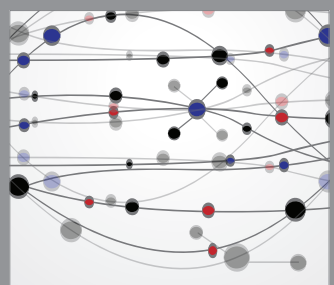

The Scientific World Journal
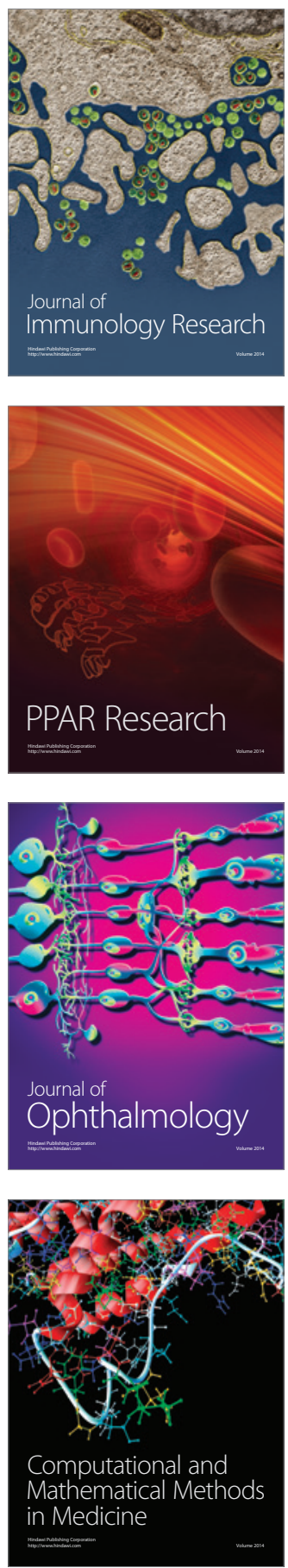

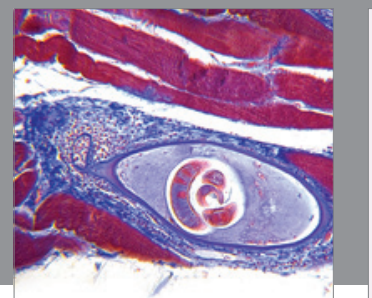

Gastroenterology

Research and Practice
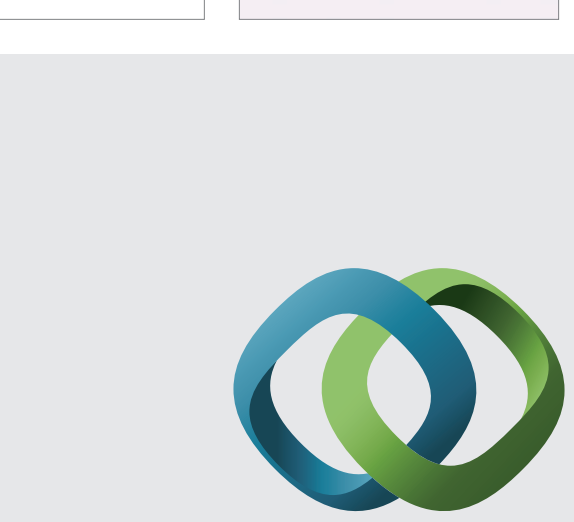

\section{Hindawi}

Submit your manuscripts at

http://www.hindawi.com
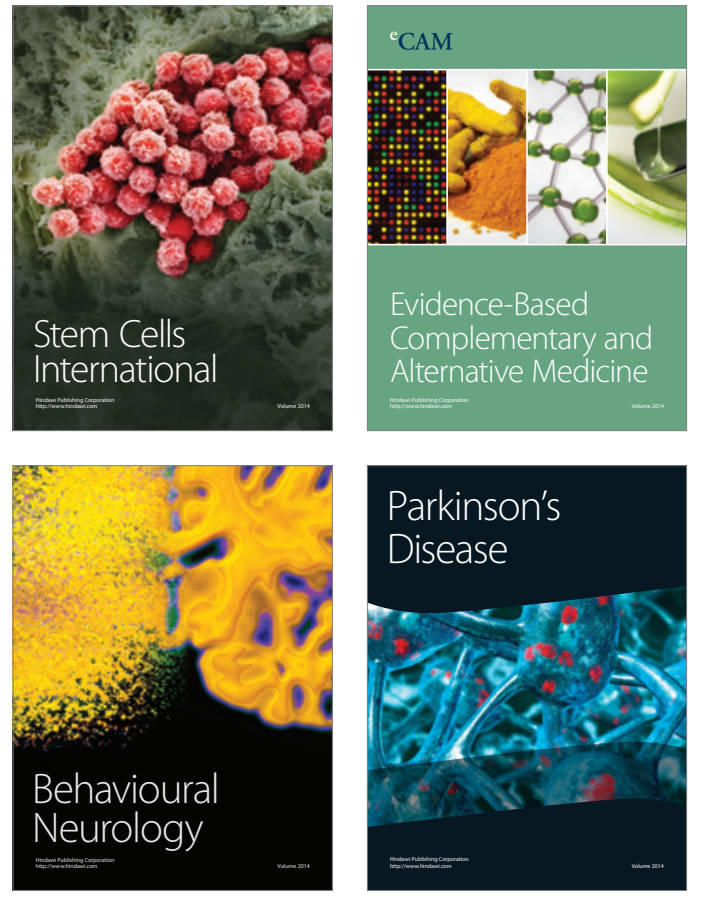
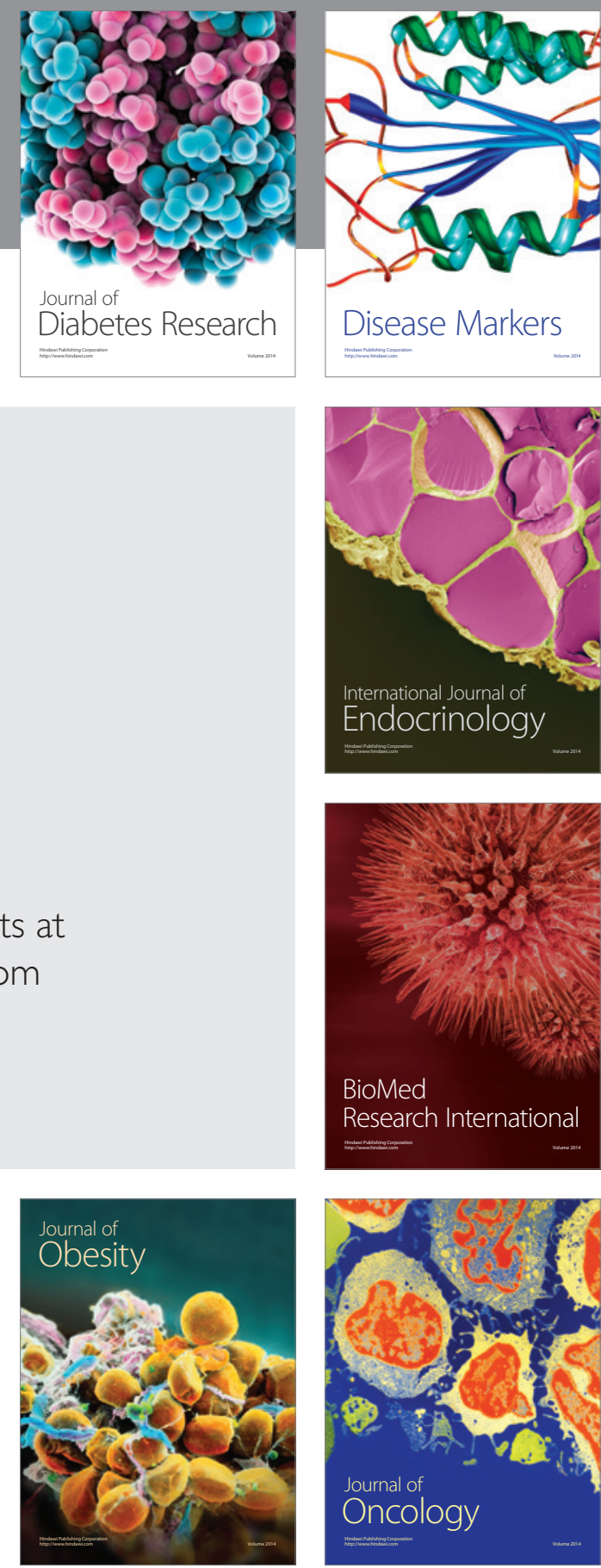

Disease Markers
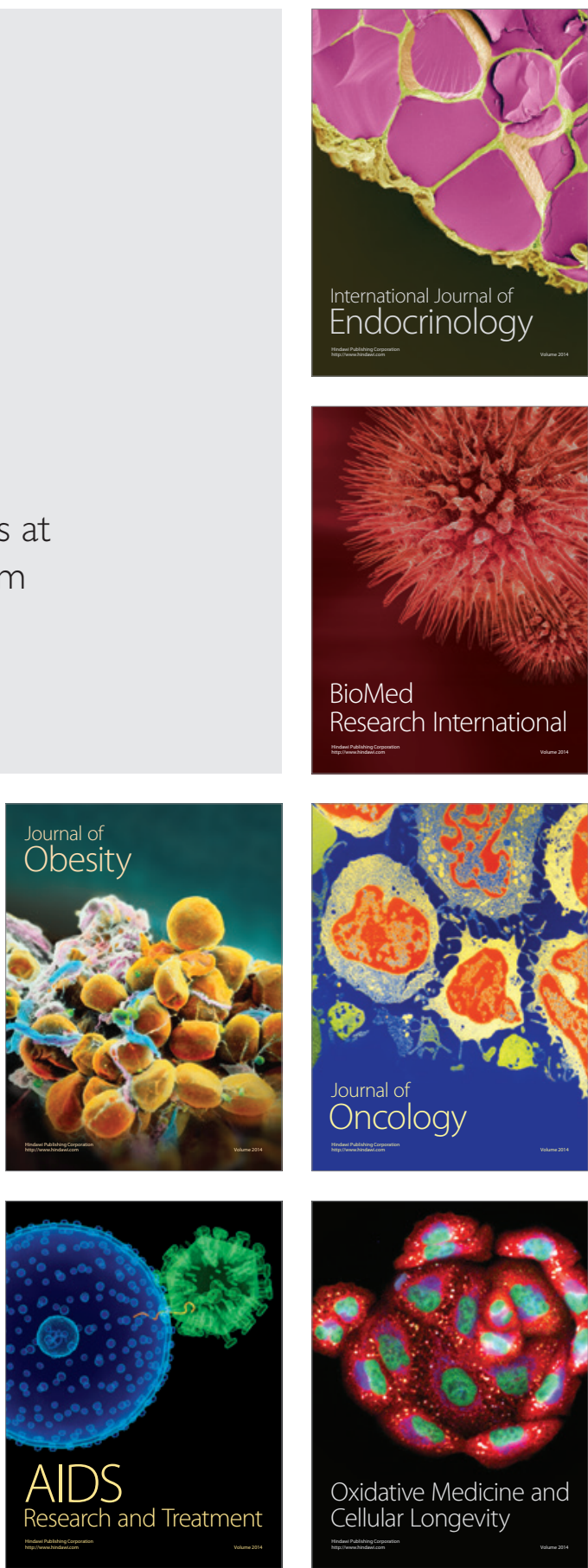